\title{
Los derechos de propiedad en Antigua Guatemala, siglo XIX. Valores liberales en instituciones de Antiguo Régimen
}

\section{Property Rights in Nineteenth Century Antigua Guatemala: Liberal Values in the Institutions of the Old Regime}

\author{
Aquiles Omar Ávila Quijas \\ Departamento de Estudios Sociales, División de Ciencias Sociales y Humanidades, \\ Universidad de Guanajuato, Campus León \\ avilaquijas@ugto.mx \\ ORCID: orcid.org/0000-0003-1040-8037
}

Resumen:

Se aborda la manera como se configuraron los derechos de propiedad en Antigua Guatemala, con base en la hipótesis de que esa municipalidad fue un gobierno que enarboló valores liberales en un marco orgánico de Antiguo Régimen. De igual modo, se estudia cómo el cabildo institucionalizó las prácticas informales que la población tenía sobre la tierra, lo que le daba una ventaja sobre el conjunto de actores racionales que se desenvolvían en esa localidad. El trabajo está fundamentado en el acervo que resguarda el Archivo Histórico de la Ciudad de Antigua Guatemala y cruza el conjunto de patrones encontrados en esa documentación con el planteamiento teórico propuesto por Elinor Ostrom sobre el gobierno de los bienes comunes. A lo largo del texto se observa que el gobierno local, en aras de mantener el control sobre las tierras, promovió de manera indirecta la generación de prácticas asociadas con el liberalismo económico del que, en acciones y discursos, trataban de huir, lo cual derivó en un proceso de perfeccionamiento de la propiedad terso y sin conflictos aparentes.

Palabras clave: enfiteusis, gobierno de los bienes comunes, tierra, laudemio, subenfiteusis, propiedad perfecta.

\section{Abstract:}

This article approaches how property rights were shaped in the city of Antigua Guatemala, based on the hypothesis that this municipality had a government that upheld liberal values within an organic framework of the Old Regime. It also studies how the population's informal land tenure practices were institutionalized through lobbying, thus providing an advantage over the set of rational stakeholders that were developing in that town. This piece of research is based on the collection of documents contained in the Historical Archives of Antigua Guatemala City, cross-referencing the set of patterns identified in this collection with a theoretical formulation proposed by Elinor Ostrom about governing the commons. The article notes that for the sake of keeping control over the land, local government indirectly promoted practices associated with economic liberalism, from which both in its discourse and actions it was attempting to flee. This led to a smooth process of perfecting the property system without any apparent conflicts.

Key words: emphyteusis, governing the commons, land, laudemium, sub-emphyteusis, perfect property. 


\section{Presentación ${ }^{1}$}

asta no hace mucho, los trabajos sobre la puesta en marcha de los principios liberales sobre la tierra, es decir, eso que Rosa Congost (2007: 76, 77) llama "el perfeccionamiento de la propiedad" se concentraban en discutir y analizar el concepto de "régimen de tenencia". Partían de una perspectiva que veía el desarrollo de la tierra como una historia de posesión-desposesión-modernización de la posesión. En otras palabras, era una historia lineal que, incluso, se esquematizaba como si las distintas formas de acceder y usufructuar el recurso fueran estáticas: en círculos concéntricos a partir del fundo legal de los pueblos (Rosas et al., 2012; Tarrio et al., 2006).

El régimen de tenencia de la tierra era un concepto que anulaba las formas dinámicas de explotación del recurso y los distintos arreglos particularmente informales que se generaban sobre este para mantener la productividad, viabilidad económica y consenso comunitarios (Mathieu, 2003: 113). Por otro lado, es un análisis que sostiene la hipótesis de victimización de los campesinos y replica el discurso liberal decimonónico sobre la imposibilidad, ya por ignorancia, ya por pereza, de los campesinos para defender sus tierras (Castellanos, 1992; 1996).

Ha supuesto también que el gobierno generó las condiciones para que un sector de la sociedad se beneficiara del proceso de perfeccionamiento de la propiedad y acaparara particularmente la tierra de los pueblos indios. Por tanto, ha suscrito la hipótesis de que, lejos del planteamiento liberal original que estableció la pequeña propiedad privada como base del crecimiento económico de los países, los gobiernos liberales promovieron la generación de latifundios (Gómez, 2000; McCreery, 1994a; 1994b).

No obstante, en los últimos años transitamos del concepto régimen de tenencia hacia el de derechos de propiedad que engloba el dinamismo de las relaciones sociales que se dan sobre el recurso, la naturaleza evolutiva de las instituciones formales e informales y entiende la tierra como un espacio sobre el que se sobreponen y yuxtaponen multiplicidad de formas de explotación, disfrute y usufructo (Congost, 2007: 39-68).

\footnotetext{
1 Agradezco el apoyo de Fabiola Abigail Afanador Rojas, estudiante de la licenciatura en Administración Pública de la Universidad de Guanajuato, Campus León. Su trabajo en la recolección de información documental ha sido fundamental para esta exposición. De igual manera agradezco la lectura, las observaciones y sugerencias de los evaluadores de este texto; nunca quedó mejor dicho \#UstedesSabenQuiénesSon.
} 
En el ínter hubo un conjunto de investigaciones que cuestionaron la linealidad en lo que hasta ese momento se había escrito sobre el tema. Surgieron trabajos que dijeron: "los indios no eran tan ignorantes como creemos", y describieron las estrategias que siguieron para mantener los esquemas de usufructo que tenían hasta antes del embate liberal-perfeccionamiento de la propiedad (Mendoza, 2006; 2007; 2008). Otros cuestionaron la hipótesis de la desposesión de la tierra al demostrar que los pueblos mantuvieron sus territorios e incluso incrementaron sus extensiones y, al contrario de la idea del régimen de tenencia de la tierra que sugería que los derechos de propiedad se modificaron tarde o temprano en pos de la propiedad privada, estas investigaciones dieron cuenta del conjunto de dificultades que se tuvieron para transitar hacia la individualización de la posesión de la tierra tanto en los pueblos indios como en los mestizos (Taracena, 1993).

El concepto de derechos de propiedad es retomado por el neoinstitucionalismo económico. La crítica que se hace a esa postura señala que estaba fundamentalmente centrado en las acciones del gobierno y dejaba de lado las relaciones sociales que se establecían a partir de dichos derechos. En este sentido, la redefinición está íntimamente relacionada con el planteamiento de Elinor Ostrom sobre el gobierno de los bienes comunes en el sentido de darle voz a los actores sociales. Por eso la definición pasa actualmente por los tamices de lo histórico, sociológico y antropológico (Congost et al., 2010: 15).

Los derechos de propiedad son ese conjunto de relaciones sociales que definen el uso que cada individuo puede hacer del recurso y que tienen que ver con el objeto sobre el cual recaen, quiénes pueden acceder a ellos, cómo son utilizados, transferidos y reforzados (Congost et al., 2010: 18-22). Por tanto, la del gobierno constituye solo una parte de todas las acciones que se ejercen sobre, en el caso de este trabajo, la tierra. Pero no soslaya lo que otros actores realizan no sólo en términos de lo establecido institucionalmente, ya sea por derecho positivo o consuetudinario, sino que enfoca lo que sale de ese marco y que se conoce como instituciones informales que, a mediano y largo plazo, condicionan las decisiones del propio gobierno y son llevadas a la institucionalidad establecida.

A lo largo de este texto se responderán un conjunto de cuestionamientos: ¿cuáles son los derechos de propiedad que se desarrollan en Guatemala a lo largo del siglo XIX? ¿Cómo convergen con la idea de perfeccionamiento de la propiedad?, y ¿cuáles son las acciones que toman para definirlos bajo la idea del nuevo esquema ideológico dominado por el mercado? Como preámbulo que permita responder, en las consideraciones finales, las preguntas que formulan 
Rosa Congost y Rui Santos (Congost et al., 2010: 22): ¿Quiénes son los actores que pueden llevar a cabo acciones específicas con los bienes? ¿Cómo son definidos aquellos que pueden convertirse en los objetos y sujetos de propiedad?, y ¿cuáles individuos o entidades colectivas tienen qué derechos?

El objetivo de este trabajo es trazar la ruta de formación y transformación de los derechos de propiedad en Antigua Guatemala a lo largo del siglo XIX, bajo la hipótesis de que el gobierno municipal fomentó un conjunto de valores liberales con instituciones de eso que esquematizamos como Antiguo Régimen. Es decir, propició una economía de mercado y fiscalización de la tierra, pilares del liberalismo económico, con recursos institucionales como la enfiteusis. Finalmente, cabe aclarar que este no es un trabajo de historia comparada, pero se utilizan los casos de otras latitudes para poner en perspectiva el proceso general de modernización que se llevó a cabo en Occidente.

Es preciso anotar, antes de seguir, que el proceso de formación de los derechos de propiedad en Antigua Guatemala cruza por dos hechos que parecen determinar el transcurrir de la historia de esa localidad. En primera instancia, es necesario no perder de vista que estaba inserta en la lógica de un gobierno general (1824-1838) que buscaba, por un lado, la organización de la sociedad sustentado en principios liberales (construcción de ciudadanía fundamentada en igualdad de derechos, educación, progreso económico a partir de la individualización de la propiedad) y, por otro, el afianzamiento de su poder frente a los gobiernos locales. En esa dinámica había dos posturas encontradas, la del gobierno de la república que pretendía privatizar la propiedad y la del ayuntamiento que buscó la manera de sortear las leyes generales para mantener bajo su administración la tierra de la municipalidad. También he dado cuenta de las contradicciones entre el discurso y los cambios en la legislación del país que derivaron en el fortalecimiento de la administración de la tierra para los gobiernos locales. En suma, lo que se puede ver es la manera como los ayuntamientos se impusieron al gobierno de la república y consolidaron ese poder tras su derrocamiento en 1838 y hasta 1877, momento en el que el gobierno de Justo Rufino Barrios decidió tomar el control político del país a partir, y esto es sólo una hipótesis, de la pauperización de los ayuntamientos (Ávila, 2014; 2017a). 


\section{Los derechos de propiedad en Antigua Guatemala}

Antigua Guatemala es un valle que se extiende a las faldas de dos volcanes, el de Fuego y el de Agua. Hasta 1775 fue la capital del Reino de Guatemala. En 1773 tuvieron lugar los "terremotos de Santa Martha", eso que hoy llamaríamos "un enjambre sísmico", que prácticamente destruyó la ciudad de Santiago de Guatemala, lo que motivó la solicitud al rey para que autorizara el cambio de lugar de esa capital. Así ocurrió, y dicha mudanza se dio entre 1775 y 1776 (Ávila, 2014; 2017b).

Mudar la ciudad no fue algo novedoso en la América Hispana. A lo largo de los siglos que siguieron a la ocupación española, el establecimiento en lo que parecía el mejor espacio para vivir por la calidad de sus recursos fue una constante. El traslado que se autorizó en 1775 era el segundo que ocurría con la capital del reino. Es decir, Nueva Guatemala sería la tercera sede que tendría. En 1541 ya se había realizado el cambio al lugar que nos ocupa y habían dejado lo que se conocería después como Ciudad Vieja. La razón había sido la misma: la actividad sísmica. El Valle de la Ermita, el espacio donde se asentó la capital a finales del siglo XVIII, tampoco estaba exento de movimientos telúricos. Pero ha sobrevivido hasta la fecha (Musset, 2001: 66-88).

La ciudad que había sido el centro político y comercial del reino quedó como un pueblo fantasma. Pocos habitantes permanecieron ahí y los esfuerzos por restaurarla no iniciaron hasta los primeros años del siglo XIX, cuando la amenaza de un brote de cólera obligó a quienes se negaron a mudarse a la nueva capital a reconstruir el acueducto y el sistema de albañales. Sin embargo, el trabajo para reparar la "gloria pasada" no empezó en forma hasta 1818, para entonces a las ruinas se les había nombrado oficialmente y se conocía como Antigua Guatemala (Rubio, 1989; Johnston, 1997). Esto abrió la puerta a la reorganización del territorio y el arranque de un proceso de "ejidalización" de la tierra bajo jurisdicción del gobierno municipal.

Aquí conviene hacer un llamado sobre la manera de abordar al gobierno local en este trabajo. Lo que vemos en la documentación a la que tenemos acceso es un patrón que nos permite prescindir de los individuos y darle al ayuntamiento la caracterización de un actor social, a saber, las acciones de las personas que formaron parte del cabildo, es decir, del órgano de toma de decisiones, nos permite plantear la hipótesis de que se trató de un cuerpo colegiado que fomentó la institucionalización del propio ayuntamiento en pos de generar certezas para el 
conjunto de actores sociales que confluían ahí. No hay, entonces, cambios drásticos en la forma de atender la problemática relacionada con la tierra. El principio que guió las distintas composiciones del cabildo fue la consecución de un beneficio fiscal para el gobierno local sin que eso mellara el crecimiento económico de sus habitantes. Por lo tanto no es extraño que a lo largo del trabajo no se haga referencia a sujetos en particular, puesto que no hay forma, en la documentación revisada, de que sus intereses hayan condicionado los acuerdos que dotaban de racionalidad a la municipalidad.

El cabildo de la ciudad se encontró ante un hecho: el espacio antigüeño necesitaba ser repoblado, pero ¿cómo atraer pobladores si el territorio estaba lleno de casas, aunque estuvieran destruidas, solares, lotes que pertenecían a alguien en propiedad particular? Pues decidió hacer uso de una figura jurídica, aunque no la menciona como tal en la documentación: la expropiación.

En este marco, cabe decir que los derechos de propiedad se fundan con el Estado. La supresión de estos es solo una forma de reconstituirse y generar una nueva organización social al suprimir a unos propietarios y dar paso a otros. La expropiación es la manifestación precisa de la prerrogativa del Estado para organizar el territorio (Azuela et al., 2005: 526, 527)

Si bien el concepto de expropiación corresponde al lenguaje jurídico del liberalismo, no era ajeno a la tradición jurídica occidental. El derecho romano contenía el principio de revocación de la propiedad por utilitas publica que, en eso que llamamos Antiguo Régimen, fue adecuado al derecho señorial bajo la figura de potestas, es decir, aquellos derechos de los poseedores de la tierra quedaban supeditados a los del señor feudal o del rey, o sea, el "dominio eminente". Principio que, al modernizarse con el liberalismo, entendería que el suelo pertenece originariamente al Estado (Fernando, 2012: 517, 518).

Desde donde se le mire, el ayuntamiento de Antigua Guatemala tuvo claro que el paso a seguir era apelar al principio de utilidad pública para trasladar el dominio de las casas y solares que estaban abandonados a su jurisdicción. Como plantean Azuela y compañía (2005: 527): "la expropiación tiene un carácter (re) fundacional". Justo lo que intentaba el cabildo de aquella ciudad.

De ese modo, en 1821 notificó a través del gobierno local de la Nueva Guatemala que aquellos que tuvieran propiedades en Antigua acudieran a demandarlas o perderían los derechos generados sobre estas, pues se tendrían por abandonadas y serían sumadas a los ejidos de la ciudad. Estableció un plazo 
perentorio y esperó. ${ }^{2}$ Esto permitió tener el control del territorio en el corto plazo y establecer políticas de repoblamiento que, por otro lado, determinaron los derechos de propiedad que se desarrollaron en esa municipalidad.

Por un lado, estaban aquellos lotes que sí fueron reconocidos por sus antiguos poseedores y que formaron parte de ese conjunto, aunque mínimo, de propiedades privadas. Lo que no sabemos es la forma como esos propietarios contribuían a la hacienda municipal y cuál era la actividad económica a la que se dedicaban.

La conversión de los predios abandonados a propiedad municipal los transformó automáticamente en propios del ayuntamiento en un proceso que ya he llamado de "ejidalización" (Ávila, 2014), es decir, de sumarlos a los ejidos de la ciudad como una estrategia para mantenerlos a salvo de los ímpetus de privatización que promovía el gobierno de la república y que exentaba a los ejidos de dicha acción. En ese momento la preocupación también estribaba sobre la manera de hacerse de recursos financieros para sostener las actividades burocráticas y de obra pública que se le demandaba al gobierno de la localidad. En el cabildo se presentó la propuesta de preparar un terreno llamado Campo de Retana para su lotificación y posterior adjudicación a todos aquellos que estuvieran interesados en tener un predio. La condición era dedicarse a la explotación de la grana cochinilla. Lo que causó aspereza en las discusiones del cuerpo colegiado del ayuntamiento fue cuál era la mejor manera de fiscalizar esa tierra. La asignación en propiedad privada ni siquiera apareció en la discusión. Unos se inclinaron por el arrendamiento, otros por el censo enfitéutico, finalmente ambos fueron utilizados. ${ }^{3}$

La enfiteusis es la cesión del dominio útil de un terreno a un individuo, con lo que obtiene el derecho a usufructuarlo a cambio de un canon o renta anual, que era un porcentaje del valor del predio que pagaba al titular del dominio directo. El contrato enfitéutico podía traspasarse o heredarse y tenía inherentes dos derechos: la fadiga y el laudemio. El primero se refiere a la posibilidad de recuperar el dominio útil de la tierra, previo pago de una indemnización al enfiteuta. El segundo es el pago que este último debe hacerle al dueño del dominio directo por la venta del útil a otro particular; generalmente era un porcentaje del precio de venta (Congost et al., 2011; Congost, 2007: 60; Ferreira, 1999: 61, 62).

El arrendamiento es un contrato que se establece entre dos sujetos jurídicos por un periodo determinado de tiempo. Lo suficientemente largo para motivar

2 Archivo Municipal de la Ciudad de Antigua Guatemala (AMCAG), Fondo Gobernación (FG), Actas del ayuntamiento constitucional, enero 23 de 1821, f. 6.

3 AMCAG, FG, Actas del ayuntamiento constitucional, abril 26 de 1821, ff. 25v y 26. 
al arrendatario a hacerle mejoras al predio y lo necesariamente corto para que el arrendador no tome ventaja de las mejoras en el contrato. Al concluir el plazo, ninguna de las partes está obligada con otra, pero pueden negociar los términos de un nuevo acuerdo. Dado que supone un convenio entre las partes, cada cierto tiempo se abre un mercado de arrendatarios. Si uno no acepta las condiciones del contrato, el arrendador puede buscar a otro (Van Bavel et al., 2010: 15).

La subenfiteusis es el contrato que un enfiteuta hace de su enfiteusis sobre un tercero. Puede ser total o parcial. En sentido estricto cede su derecho al dominio útil de un predio a cambio de una renta o de la amortización del canon al que está obligado. No es una transferencia de su posesión, por lo que las obligaciones pecuniarias siguen siendo del enfiteuta (construcción propia con base en Gallego, 1998: 207).

Si pensamos que el momento de fundación del Estado es también el de la creación de la propiedad, el cabildo de Antigua Guatemala constituyó el poder político superior del gobierno local por encima de los intereses de los particulares, al tomar el control de su territorio, por un lado; y crear una nueva organización social al generar nuevos poseedores de la tierra, por otro.

Si prestamos atención, lo que Antigua Guatemala hizo fue generar bisagras entre el nuevo orden político-ideológico establecido en el mundo occidental y las prácticas que se tenían en el orden colonial. Se trataba de un gobierno con ciertos aires liberales y, a la vez, de Antiguo Régimen, pero que logró empatar ambos sin que eso derivara en conflicto entre sus habitantes. Por ejemplo, asumió que al tener el control de su territorio era posible establecer un censo de la tierra que tenía dada en enfiteusis, de propiedad privada, y la que estaba otorgada en arrendamiento. Parece que no se hizo, pero fue una discusión que se presentó en el cabildo. No obstante, había claridad sobre la fiscalización de los distintos derechos de propiedad de acuerdo con los becerros. Ahí estaba definidos como "terrenos" (que fueron cobrados en el periodo 1832-1834) aquellos lotes que se habían entregado ya fuera en enfiteusis o en arrendamiento; "calles y callejones" (1832-1867), la extensión que los particulares hacían de sus predios sobre las calles y callejones de la ciudad y por los que se cobraba un canon; "casas" (1833-1867), aunque no hay una continuidad en su cobro ni información que nos permita entender a qué se referían con este concepto solo podemos aventurar la hipótesis de que se trataba de los espacios que eran adquiridos a través de la facultad económico-coactiva y que luego integraban a los ejidos de la ciudad; "ejidos" (1834-1870), se refiere a todos aquellos espacios dados bajo la figura del 
censo enfitéutico o el arrendamiento; "laudemios" (1846-1870), en cuanto respecta al cobro que el ayuntamiento hacía de los traspasos y subenfiteusis que se hacían entre los particulares; "venta de terrenos" (1844-1845), como su nombre lo indica, la unificación de dominios (véase figura 1).

Figura 1. Porcentaje de ingresos por derechos de propiedad con respecto al total de ingresos (1832-1870).

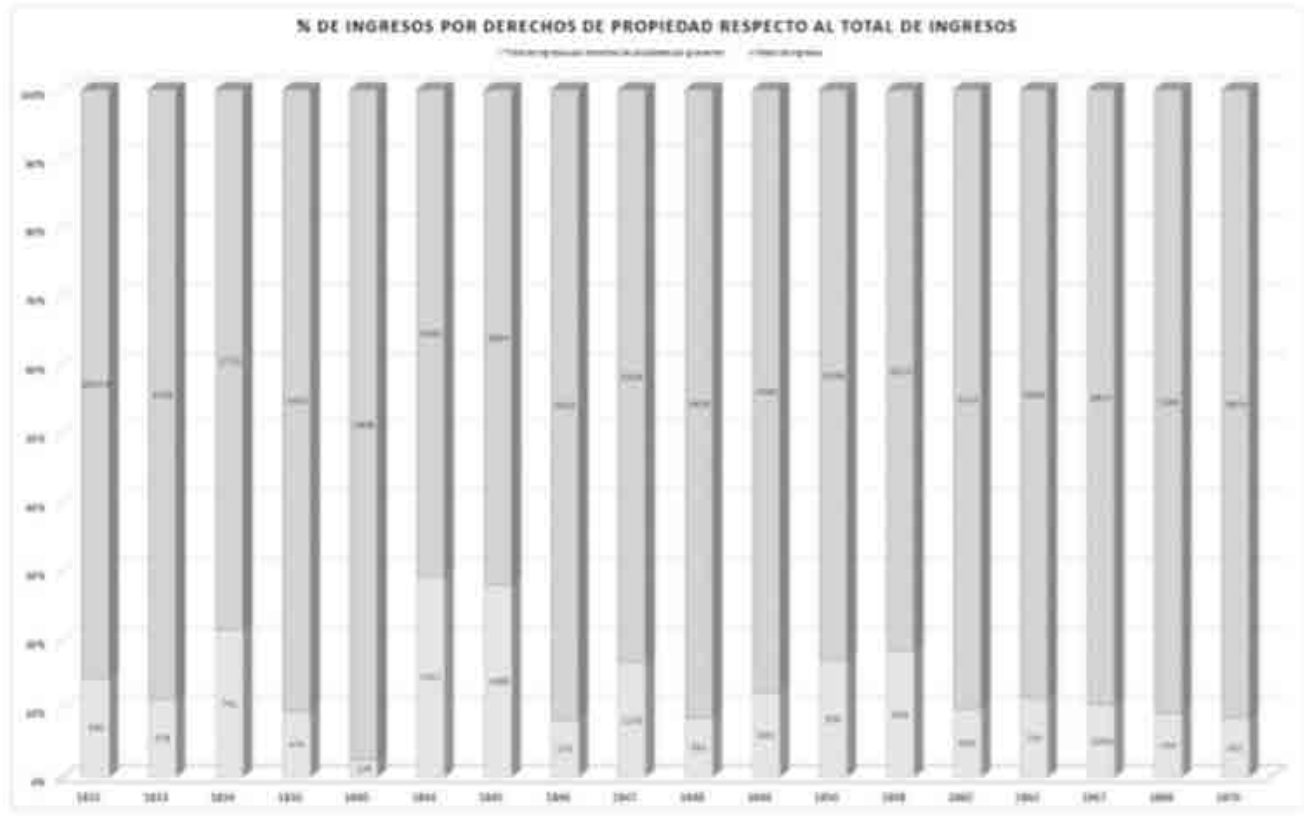

Fuente: Elaboración de Fabiola Abigail Afanador Rojas, con la información de AMCAG, Fondo Tesorería, Ramo Cuentas municipales.

Lo que puede verse en la gráfica presentada permite cuestionar el argumento de Luis Juventino García Ruiz (2015: 36), quien señala que la propiedad imperfecta tenía como fin la recuperación fiscal del ayuntamiento. Aunque páginas adelante él mismo reconoce que eso no fue posible, exactamente igual que en el caso antigüeño. Pero en ambas experiencias lo que puede recuperarse es el sentido moderno de la fiscalidad, pues no se fiscalizó el trabajo, sino la tierra, lo que era un paso adelante con respecto al Antiguo Régimen. Tan es así que, en buena medida, como lo plantea García Ruiz y los datos que aquí se presentan, no había una burocracia especializada en el cobro de este tipo de impuestos, de tal suerte que su recolección es más bien errática. 
El gobierno de Antigua Guatemala utilizó valores políticos de Antiguo Régimen para organizar su territorio y sociedad. Aunque no tiene gran importancia en el total de impuestos cobrados, el cabildo entendió que gravar la tierra era el paso inevitable como parte de su conversión en el actor político primordial. Si bien hay una larga tradición de reconocimiento de señorío, este no correspondía a los términos de un sistema fiscal que gravara la tierra como fuente de riqueza, sino que era parte de un conjunto de acciones en función del reconocimiento de la superioridad social de un actor específico. En el caso que nos interesa se tuvo claro que al dotar de un terreno a un particular se haría con la finalidad de darle herramientas para su desarrollo económico. Al ser la tierra un propio del ayuntamiento tenía que cooperar con el desarrollo de la ciudad vía su fiscalización.

La prueba de que eran gravámenes que no estaban en el imaginario y, por tanto, no eran prioritarios es que, a pesar de tener la posibilidad de hacerlo, nunca realizaron un censo de las tierras y por tanto una mejor organización en la forma de cobrar los impuestos. Lo que, sin embargo, parece contradictorio con el uso de la facultad económico-coactiva que no dudaron en utilizar en algunos casos. Es decir, no buscaron una manera efectiva de cobrar los tributos según cada derecho de propiedad, como puede verse en la gráfica, pero no dudaron en hacer efectivo el pago de las obligaciones fiscales cuando se dieron cuenta de que algunos no lo habían hecho. Si algún vecino no cumplía con sus obligaciones, el gobierno local embargaba el bien inmueble y lo daba en enfiteusis a alguien más. ${ }^{4}$ También se encuentran casos de personas que abandonaron las fincas o los sitios por no poder cumplir con el pago anual al que estaban comprometidos. ${ }^{5}$

\section{Los arreglos institucionales sobre la tierra}

La teoría institucionalista señala que los actores sociales deben tener certezas sobre las acciones que pueden desarrollar en el marco de un contexto jurídico con la finalidad de que adquieran racionalidad y límites (Poteete, 2012: 83-109). En este sentido, el ayuntamiento de Antigua desarrolló varios esquemas de adjudicación de predios según el modelo de fiscalización a seguir, es decir, dotó de certidumbre a los pobladores. Esta acción muestra que el gobierno de la otrora

\footnotetext{
4 Por ejemplo, AMCAG, FA, RP, "Embargo que el ayuntamiento hace el Sr. Antonio Padilla", abril 24 de 1851, s./f.

5 Por ejemplo, AMCAG, FA, RP, “Dolores Asturias regresa al ayuntamiento la casa que tiene arrendada por no poder pagar el canon anual", marzo 27 de 1953, f. 6.
} 
capital del reino de Guatemala entendió la necesidad de entrar en la dinámica liberal, algo iniciado en Europa décadas atrás y que generó un proceso de larga duración con debates y acciones centrados en la reformulación de los derechos de propiedad. A la postre tendría lugar una modificación tributaria.

En este sentido, es preciso apuntar que en Europa hubo una reformulación de las relaciones de propiedad entre los señores y los siervos. La dinámica liberal dejó atrás las señoriales para establecer mecanismos de obtención de rentas fincados en la tierra, no en el trabajo. De ese modo, la servidumbre transitó hacia formas en que el arrendamiento se convirtió en el principal derecho de propiedad en las otrora tierras feudales. Lo anterior daría paso a la discusión sobre si un campesino libre tomaría mejores decisiones en pos de su productividad y se concluyó que lo mejor era dotarlos de derechos de propiedad plenos y eliminar el vínculo con el dueño de la tierra (Béaur et al., 2013).

Parece haber un acuerdo en el sentido de que el mundo occidental transitó hacia la decisión de los gobiernos de generar condiciones de seguridad jurídica a los campesinos sobre su tierra, incluso si eso significaba menguar el poder económico de los señores feudales. Se partió del principio de que el desarrollo individual promovería el general. Lo que se inserta en la lógica de aquello que hemos dado en llamar "despotismo ilustrado". Esta misma idea fue desarrollada por Jovellanos y Campomanes. García Ruiz (Ruiz, 2015 y Ávila, 2014), de hecho, describe cómo esa discusión estuvo presente en el cabildo de Veracruz y terminó con la modificación de los derechos de propiedad de los mayorazgos en favor de los campesinos por medio de la enfiteusis. Eran reformas agrarias que también se llevaban a cabo en Europa; por ejemplo, el caso de lo que hoy es Dinamarca, donde de manera paulatina a lo largo del siglo XVIII y XIX, los dueños de la tierra vieron disminuidas sus posesiones en favor de derechos de propiedad plenos para los campesinos.

En aquella región, a principios del siglo XVIII se inició un proceso en el que el Estado comenzó a poner límites a los derechos de propiedad de los señores feudales, en primera instancia, y con el tránsito de la servidumbre al arrendamiento evitó rentas onerosas a través de gravámenes a los dueños de la tierra. Luego buscó la manera de abolir el trabajo gratuito (corveé) al que la costumbre obligaba a los campesinos para con el señor feudal. Después de 1730 se presentaron tres proyectos de reforma de los derechos de propiedad: 1) Abolición del trabajo gratuito; 2) Certezas jurídicas a los arrendatarios sobre su posesión; 3) Lotificación de los dominios (demesnes) del señor feudal. En 1770 se operó una 
reforma agraria y se comenzó con las tierras reales. Optaron por el modelo inglés de cerramiento de las posesiones (enclosures). Los campesinos obtuvieron propiedad plena de esas tierras y solo se comprometieron, a cambio, al pago de una renta fija a la corona. Lo que siguió fue extender la reforma al resto de dominios señoriales, no sin la resistencia y oposición de los señores feudales que argumentaron sobre los beneficios del trabajo gratuito. La reforma se llevaría a cabo con el apoyo de algunos terratenientes que la asumieron como una posibilidad de entrar a la economía de mercado (Porskrog, 2010: 126-136).

El caso de Dinamarca sirve para entender las modificaciones que se hicieron en la manera de relacionarse con la tierra. Que el rey haya puesto sus dominios en la economía del mercado no solo marcaba la pauta del posterior diseño institucional que tendrían los derechos de propiedad en relación con los campesinos y los señores feudales, sino que estableció el antecedente de una reforma fiscal sustentada en la posesión de la tierra y no en el trabajo que se hiciera en ella. Esa variante se adoptó en Antigua con la enfiteusis y el arrendamiento.

Johnston Aguilar (1997) afirma que los nuevos pobladores ocupaban casas y sitios abandonados con la autorización del gobierno local, el cual los obligaba a comprometerse a pagar su valor o el arrendamiento respectivo en caso de que el dueño apareciera. En el primer caso, el gobierno local tendría la respuesta unos años después: en 1821 el ayuntamiento notificó a través del cabildo de la Nueva Guatemala que aquellos que tuvieran propiedades en Antigua acudieran a demandarlos o perderían sus derechos de propiedad. Así, las que no fueron reclamadas se agregaron a los ejidos del ayuntamiento, como ya se ha señalado.

Si bien la regularización de los predios ya ocupados antes de la municipalización de los baldíos en 1821 fue una constante a lo largo de esa década, el ayuntamiento comenzó a fraccionar y repartir los terrenos de ejidos a los particulares, ya a censo enfitéutico, ya en arrendamiento. Aunque después de 1830 el arrendamiento fue poco utilizado y se prefirió la enfiteusis.

El cabildo de Antigua Guatemala acordó en 1823 que con el fin de estimular la siembra de nopal y con ello la producción de grana cochinilla, se fraccionarían y repartirían los terrenos del Campo de Retana, ubicado al Oeste de la ciudad, con una laguna contigua y franqueado por el río Guacalate, para lo cual comisionaron a dos vecinos para que hicieran la medición del terreno y ofrecieran en su informe un proyecto de fraccionamiento para estar en posibilidades de adjudicarlo. ${ }^{6} \mathrm{La}$ propuesta fue que el terreno se partiera en manzanas de 120 varas cuadradas $(0.7$

\footnotetext{
${ }^{6}$ amcag, Actas del Ayuntamiento Constitucional, mayo 16 de 1823, s./f.
} 
hectáreas) y le asignaron el canon de cinco pesos anuales a cada una. ${ }^{7}$ La asignación sería directa, es decir, no habría subasta, tampoco se otorgaría más de una manzana, por lo que se nombró una comisión que convocara a los interesados, adjudicara los lotes y extendiera los títulos correspondientes. ${ }^{8}$

Los siguientes terrenos que se fraccionaron y repartieron fueron el Calvario y el Campo de Santa Lucía, que quedaron desocupados después del traslado de 1775. Se puede deducir, pues a la fecha no se ha localizado la documentación que permita afirmarlo, que se siguió el mismo esquema anterior y el repartimiento se dio entre finales de 1823 y 1824 . Es decir, se fraccionaron los terrenos en lotes o manzanas y luego fueron directamente adjudicados a los interesados, con la salvedad de que en el Campo de Santa Lucía el canon fue establecido en 10 pesos por lote. Finalmente, con la intención de fraccionarlo y repartirlo vía adjudicación directa, se mandó medir y proyectar la lotificación de los cerros del Manchén y Santa Cruz, al este de Antigua, aunque la documentación no permite saber si se llevó a cabo el reparto o no. ${ }^{10}$

Estos ejidos fueron dados a los vecinos a censo enfitéutico. En primera instancia se propuso un canon anual discrecional que generó conflictos, de tal suerte que el cabildo dictó un acuerdo para normar el pago por reconocimiento de la titularidad del dominio directo según el cual los enfiteutas tendrían que pagar sus censos de acuerdo con la fertilidad del terreno y oscilaría entre dos, tres o cuatro pesos por cada 40 varas cuadradas. ${ }^{11}$ Aunque la discrecionalidad se mantenía intacta, pues no hubo una definición de cómo medir la fertilidad del terreno.

A partir de 1826 no existe evidencia de que hayan vuelto a lotificar y adjudicar predio alguno; sin embargo, comenzó un proceso que se podría denominar de denuncia-subasta-adjudicación. El gobierno local prefirió que los terrenos baldíos fueran denunciados por los interesados, aunque el denunciante no tendría, por el hecho de serlo, preferencia alguna en la dotación, ya que el predio sería adjudicado a quien ofreciera más dinero. Este esquema duró poco; la lógica de la denuncia obliga a pensar en una adjudicación directa al denunciante, por lo que pronto se cambió la estrategia de entrega de predios.

\footnotetext{
7 AMCAG, Actas del Ayuntamiento Constitucional, noviembre 26 de 1825, s./f. La conversión a metros cuadrados del área con base en Menocal Villagrán, 2011: 68.

8 AMCAG, Actas del Ayuntamiento Constitucional, junio 6 de 1823, s./f.

9 AMCAG, FG, Actas Municipales, marzo 4 de 1825.

10 AMCAG, FG, Actas Municipales, agosto 26 de 1825, s./f.

11 AMCAG, FA, RE, Acta del ayuntamiento de Antigua en el que solicitan la aprobación del presupuesto para remedir los ejidos municipales y reestructurar el canon anual, julio 24 de 1833, ff. $4 \mathrm{v}, 5$ y $5 \mathrm{v}$.
} 
A partir de ese momento, el interesado tenía que solicitar el terreno. El cabildo, tras el informe que levantaba un regidor sobre la existencia y disponibilidad del predio, ordenaba su medición y valuación, lo que servía para dar un valor de salida; en seguida anunciaba que se remataría en subasta pública, y convocaba en fecha y hora precisas. Como ya se dijo, al ser un remate público, quien ofreciera un mejor valor al de salida era a quien se le adjudicaba. Para beneficio de las arcas públicas lo idóneo era que se presentaran al menos dos postores por remate; sin embargo, no siempre sucedía así, en algunas ocasiones solo se presentaba quien lo había solicitado, por lo que el arrendamiento se tenía que calcular con base en el precio de salida. Acto seguido se daba paso a la titulación y adjudicación. El título era un documento que se otorgaba al enfiteuta, en el que quedaba asentado el lote que se otorgaba, su área y linderos, el valor y el precio del canon anual, que debía satisfacer a las arcas municipales. Asimismo, se describía la subasta pública en la cual fue otorgada, sus condiciones, y se dejaba constancia del aval que presentaba el interesado. ${ }^{12}$

Sin embargo, el ayuntamiento no generó mecanismos para establecer un seguimiento de las rentas pagadas, así que a veces era sorprendido con la petición de "terrenos abandonados" que resultaban estar arrendados a alguien en particular. Como el caso del Astillero, que es el ejemplo de las carencias burocráticas del gobierno local (Ávila, 2012).

El Astillero era un terreno ubicado a las orillas del territorio antigüeño hacia al suroeste, lindaba con el río Guacalate, una corriente de agua perenne que abastecía, junto con el río Pensativo, a Antigua en sus requerimientos urbanos y agrícolas, así como a varios pueblos y propiedades privadas más.

Como sucedió con otros predios, el ayuntamiento no sabía cuáles eran los derechos de propiedad correspondientes a El Astillero. En 1819 le fue solicitado al gobierno que sacara a subasta pública ese terreno, ${ }^{13}$ y así se enteró de que era parte de los ejidos de Antigua y que José Antonio Sánchez lo había arrendado hasta su muerte, luego su viuda se lo traspasó a Nicolás N., quien lo abandonó, por lo que no reportaba beneficio alguno. El ayuntamiento ordenó una investigación para saber el estado de ese arrendamiento, pero no se localizó la documentación relativa y las indagaciones entre los individuos llevaron a la conclusión

12 Por ejemplo, puede verse AMCAG, FA, RP, "Título de posesión expedido a José María Cornejo", diciembre 24 de 1836, s./f.; amcag, fa, rp, "Título de posesión expedido a Nicolás Larrave" en Expediente en que consta la medida del astillero y sus poseedores, ff. 28v-29v.

13 AMCAG, FA, RP, Exp. en que consta la medida del Astillero, "Solicitud de arrendamiento del Astillero que hizo Juan Gualberto Velú", enero 22 de 1819, f. 4. 
de que, efectivamente, el último arrendador había sido José Antonio Sánchez. ${ }^{14}$ Dado lo cual no existía impedimento para que se subastara. Se apercibió a la población a través de carteles. El arriendo sería por nueve años con 10 pesos anuales como precio de partida de la subasta. ${ }^{15}$ La ganó Miguel Marroquín, quien pujó hasta los 18 pesos. ${ }^{16}$ Si bien Marroquín tenía la obligación de pagar el arrendamiento hasta 1828, lo traspasó en 1825 a Francisco Fernández sin darle aviso al gobierno local, por lo que se dejó de pagar el arriendo. Sin embargo, las autoridades no se dieron cuenta hasta 1830, porque otro vecino, Matías Coronado, solicitó el arrendamiento del terreno al percatarse de que estaba abandonado. ${ }^{17}$

Es necesario resaltar aquí que el ayuntamiento de Antigua dotó de límites precisos a los actores sociales sobre el conjunto de acciones que podrían o no llevar a cabo y les dio certeza jurídica a través de la adjudicación, el arrendamiento, la denuncia, la subasta y la titulación de los derechos de propiedad que tenía sobre los terrenos específicos, lo que era una garantía sobre la posibilidad de conflictos entre los particulares.

\section{Los arreglos informales (institucionalizados)}

Una de las características del ayuntamiento antigüeño fue su capacidad para adaptarse a los arreglos informales que se gestaban en su población. Esta institucionalización determina su adecuación al contexto y la posibilidad de respuesta para mantener a los actores sociales en un esquema de racionalidad política.

En la etapa posterior al temblor de finales del siglo XVIII y al abandono de la ciudad, calles y callejones fueron utilizados como sementeras. La definición del espacio urbano se difuminó. En ese periodo de reorganización, fraccionamiento y reparto de los ejidos de la ciudad, el cabildo acordó, que para no desprenderse del dominio directo que le pertenecía, se les cobrara a los vecinos que estuviesen aprovechando calles y callejones una cuota anual de 12 reales por cuadra,

\footnotetext{
14 AMCAG, FA, RP, Exp. en que consta la medida del Astillero, "Reporte de las diligencias llevadas a cabo para conocer el estado del Astillero", febrero 6 de 1819, f. 4v.

15 AMCAG, FA, RP, Exp. En que consta la medida del Astillero, "Remate del Astillero" febrero 9 de 1819, f. 4v.

16 AMCAG, FA, RP, Exp. En que consta la medida del Astillero, "Remate del Astillero" marzo 20 de 1819, f. 3.

17 AMCAG, FA, RP, Exp. En que consta la medida del Astillero, "Solicitud de arrendamiento del Astillero que hizo Matías Coronado" septiembre 17 de 1830, f. 4v.
} 
y ordenó se levantara un padrón con los sujetos a quienes se les debía cobrar. ${ }^{18}$ Pero no se limitó a las personas que ya estaban aprovechando las calles y callejones. La municipalidad siguió otorgando a censo aquellas que si bien estaban trazadas, no eran utilizadas con frecuencia. Por ejemplo, en 1844, Rafael Segura y Carlos Sol acudieron a la municipalidad para manifestar que la entrada de los sitios que tenían concedidos a censo enfitéutico la daba un callejón que, según su dicho, no tenía tránsito alguno, razón por la cual acudían a la municipalidad a solicitar que se les diera en partes iguales, comprometiéndose al pago del canon establecido. ${ }^{19}$

En 1849 se practicó la medición del terreno que se había dado en enfiteusis a Vicente Carranza. El lote colindaba con un callejón en el cual había una zanja para conducir agua al terreno adyacente, que pertenecía a Mariano Mirot; el juez dio parte del hecho a la municipalidad, la cual, al caer en la cuenta de que este último no había solicitado el uso de dicho callejón, procedió a multarlo. Lo que cabe destacar es que la pena pecuniaria no fue dada a partir del uso indebido de un bien de dominio público, sino porque no lo había pedido a censo, dejando de pagarle a la municipalidad el canon correspondiente. ${ }^{20}$

No queda claro cuándo fue el momento en el que la subenfiteusis comenzó a ser una práctica común en los derechos de propiedad que se establecieron en Antigua. La primera referencia al respecto apareció en un documento en el que "por cortesía" se le informó al gobierno local del hecho. A partir de eso, solicita que quienes recurran a esa práctica informen al ayuntamiento. Pero, por alguna razón que no aparece en la documentación, comenzó a demandar el laudemio de cada traspaso. La práctica era tan habitual que incluso el becerro de ingresos contenía un apartado exclusivo para ese concepto. Y el cobro derivó en una discusión epistolar entre uno de los enfiteutas y el gobierno, que le exigió y le hizo pagar el laudemio correspondiente. Se pueden observar tres momentos que permiten identificar la subenfiteusis. El primero es el aquel que ocurre entre 1824 y 1828 cuando se lotifican y asignan a los particulares terrenos a censo enfitéutico. El segundo, alrededor de 1836 y hasta 1840, al iniciar los traspasos de los censos, de lo que solo se informaba al gobierno local como un gesto de "cortesía". El último, que parte de 1840 en adelante, en el momento en que el ayuntamiento comienza a cobrar el laudemio por cada traspaso. Estos no solo se

\footnotetext{
18 AMCAG, Actas del Ayuntamiento Constitucional, mayo 9 de 1823, s./f.

19 AMCAG, FP, RCYC, "El Sr. Rafael Segura y Carlos Sol solicitando un callejón”, mayo 5 de 1844.

20 AMCAG, FP, RCYC, "Medida del terreno de Vicente Carranza", noviembre 6 y diciembre 9 de 1849.
} 
establecían por la enfiteusis en su totalidad, sino que los terrenos en divididos y cada sublote entregado a un particular que firmaba un contrato con el enfiteuta para darle cada año un porcentaje del total del canon que debía pagar. Ese contrato no trasladaba la obligación fiscal a los subenfiteutas, se mantenía en el original, ellos solo cooperaban para que año con año pudiera cumplir con el ayuntamiento. Algunos compartían la tierra, otros dividieron su terreno y solo se dedicaban a cobrar el subcanon respectivo.

Sin embargo, en junio de 1859 un vecino le notificó a la municipalidad que fraccionaría y arrendaría el lote que tenía dado a censo enfitéutico. Aclaraba que él seguiría pagando el canon correspondiente y que su aviso no buscaba la autorización del cabildo sino que era solo un gesto de buena voluntad. El gobierno local entendió que ese lote sería traspasado, por lo que procedió a solicitar el pago del laudemio a cambio de su visto bueno. Esto motivó un extenso oficio en el que se aclaraba que los arrendantes no adquirirían obligación alguna con la municipalidad pues el enfiteuta no cedería sus derechos sobre el predio, por lo que el canon sería pagado por él en los términos del título que tenía dado a su nombre con el producto del fraccionamiento y arrendamiento que hacía de este. Razón por la cual el pago del laudemio era improcedente. Para aclarar la situación mencionó que el alcalde segundo había seguido idéntica estrategia con un predio arrendado a una vecina a quien le pagaba el canon establecido por la municipalidad, mientras que él gozaba de los beneficios de la cosecha de grana que llevaba a cabo en aquel terreno sin tener un título que amparara su posesión y le generara obligaciones con la municipalidad. Esto era lo mismo, por lo que la idea de extender un título a los arrendantes no aplicaba, ni tampoco el laudemio. ${ }^{21}$

El decreto de enero 8 de $1877^{22}$ ordenó la unificación de dominios a través de la redención de censos enfitéuticos, así como la titulación de los terrenos. La exposición de motivos es clara en el sentido de que la enfiteusis sirvió para distribuir la tierra, pero era una figura que dificultaba la libertad mercantil y, por lo tanto, el desarrollo agrícola. En consecuencia, se hacía obligatorio a todos los censatarios redimir la enfiteusis de la que gozaban y se prohibió que en adelante las municipalidades la usaran para fraccionar y adjudicar a particulares sus ejidos.

En el caso de Antigua Guatemala el decreto de redención de censos enfitéuticos no generó cambio drástico alguno en la tenencia de la tierra, más de medio siglo de tener esa institución como la principal vía de acceso al usufructo de al-

\footnotetext{
21 AMCAG, Documentos sin clasificar, "Negación de traspaso", agosto 1 de 1859, s./f.

22 Recopilación, Decreto 170, enero 8 de 1877, que ordena la redención de los censos enfitéuticos, pp. 90-93.
} 
gún predio permitió que la transición de la división de dominios a la propiedad plena fuera en general tersa, aunque lenta. Entre 1877 y 1890 se redimieron 118 predios, un promedio de nueve por año. ${ }^{23}$

El ordenamiento previó únicamente aquella tierra que ya había sido fraccionada y adjudicada en enfiteusis, y mantuvo bajo administración municipal la que fuera "efectivamente" utilizada por el común del pueblo. En este punto cabe entonces preguntarse ¿cuál era el fin de la redención de los censos enfitéuticos? Para el programa liberal la tierra tenía que ponerse a circular en el mercado. Su privatización era condición sine qua non para tal fin.

La enfiteusis, sin embargo, permitía la movilidad de la tierra a pesar de la división de dominios. De hecho, en los considerandos del decreto se establece que los censos enfitéuticos habían servido para la distribución de la tierra de una manera más o menos igualitaria. Por otra parte, el decreto no liberó del pago de un impuesto las transacciones de predios entre los individuos, el traspaso de los censos generaba el cobro de un laudemio a favor del poseedor del dominio directo, en este caso de los ayuntamientos. El régimen liberal impuso una alcabala a la traslación de dominio de los bienes inmuebles de $1 \%$ sobre el valor del contrato. ${ }^{24}$ Aunque no aplicaba para los censatarios, aquellos que tenían propiedad plena sobre sus lotes también debían pagar una contribución territorial fijada en dos pesos anuales por cada caballería, que luego disminuyó a un peso. ${ }^{25}$

En el caso de Antigua Guatemala el decreto de redención de censos enfitéuticos no generó cambio drástico alguno en la tenencia de la tierra, más de medio siglo de tener esa institución como la principal vía de acceso al usufructo de algún predio permitió que la transición de la división de dominios a la propiedad plena fuera en general tersa, aunque lenta. ${ }^{26}$

Los conflictos que se suscitaron no fueron en torno a los predios mismos, como ya se planteó. La enfiteusis permitió repartir los ejidos y organizar el territorio. Prueba de esto es que no parecen existir conflictos entre los vecinos por los límites establecidos o por invasiones. Recuérdese que la enfiteusis antigüeña requería la existencia de un acta que asentaba el área del predio y los linderos, de tal suerte que para la redención solo era necesario presentar dicho documento, sin la intervención de agrimensores ni de litigios. Los problemas se dieron sobre

\footnotetext{
${ }^{23}$ AMCAG, FA, RP, "Índice de los censos redimidos", sf, s./f.

24 Decreto 110, El Guatemalteco, enero 31 de 1874.

25 Decreto 108, El Guatemalteco, diciembre 8 de 1873; Decreto 132, El Guatemalteco, enero 28 de 1875.

${ }^{26}$ AMCAG, FA, RP, "Índice de los censos redimidos", sf, s./f.
} 
el monto de los capitales a redimir. En algunos casos el total les pareció excesivo. Cabe recordar que el valor del predio o de la casa asentado en el acta solo era un referente para establecer el canon anual que se debía pagar y que representaba un porcentaje, usualmente de $2 \%$ o $3 \%$, dependiendo de la calidad de la tierra, del total. Por lo que ante la necesidad de pagar el valor de los terrenos, algunos vecinos solicitaron se volviera a valuar, con el fin de llegar a un "precio justo". ${ }^{27}$

La respuesta del ayuntamiento de Antigua al decreto de redención de censos fue, por decirlo de alguna manera, sutil. Dejó de dar sus ejidos a censo enfitéutico, pero retomó el arrendamiento que había abandonado en la década de 1830 como una vía para dotar de tierra a sus habitantes, a pesar de que las solicitudes de los interesados expresamente pedían la enfiteusis. De hecho, hacerlo no iba contra la letra de ley, quizá contra su espíritu, pero ese es campo de las interpretaciones. La normativa señalaba que a partir de su promulgación, los ejidos no serían dados a censo, sino en propiedad plena. Pero nunca menciona el arrendamiento. Aunque también hubo formas manifiestas de resistencia.

Por ejemplo, en 1885 fue solicitada a censo la plazuela de Belén y el ayuntamiento respondió que dicho predio sólo podía otorgarse en arrendamiento por 10 años. ${ }^{28}$ En ese mismo año recibió la solicitud del heredero de un vecino de Antigua para traspasar el terreno que a censo le habían otorgado a su padre, el gobierno aprobó el traspaso con la condición de que presentara un fiador que garantizara el pago del canon correspondiente. ${ }^{29}$ Este último caso es de llamar la atención pues representaba una afrenta directa al decreto 170. En teoría, la municipalidad no debió autorizar el traspaso pues el enfiteuta debió haberlo redimido primero, o devuelto el dominio útil a la municipalidad para que esta lo sacara a subasta pública y procediera su enajenación en los términos del ordenamiento referido. Sin embargo, el cabildo operó en los términos en que lo había hecho antes de la reforma liberal y autorizó el traspaso.

Como puede verse, lo que el ayuntamiento de Antigua Guatemala propició a lo largo del siglo XIX fue la circulación de la tierra, es decir, promovió, al interferir lo menos posible, la creación de un mercado de tierras que en la última de las instancias marcó las características de los derechos de propiedad: No había una vinculación personal a la tierra. El vínculo era meramente económico. Es decir,

27 Por ejemplo, AMCAG, FA, RP, "Solicitud de avalúo de una casa", abril 24 de 1877 y "Avalúo de la finca del señor Manuel Gálvez", noviembre 6 de 1881.

28 AMCAG, FA, RP, "Solicitud a censo de la plazuela de Belén", enero 25 de 1892.

29 AMCAG, FA, RP, "Traspaso del censo de un cuchilla", junio 9 de 1885. 
se inscribe en la lógica del marco ideológico general de la época: el progreso general tendrá lugar si se crean las condiciones para el individual.

\section{Consideraciones finales}

Rosa Congost y Rui Santos (Congost et al., 2010: 22) plantean un conjunto de preguntas claves sobre los derechos de propiedad que considero pueden servir de colofón a este texto:

¿Quiénes son los actores que pueden llevar a cabo acciones específicas con los bienes?

Como pudo observarse a lo largo de este trabajo, hay tres actores que ejecutan acciones racionales sobre la tierra, que es el bien que nos ocupa: el gobierno municipal, al hacerse del recurso a través de los mecanismos que tuvo a la mano. Si bien es cierto que en la documentación no hay un respaldo legal para eso que aquí hemos llamado expropiación, también es cierto que no hay manifestaciones judiciales en contra de las decisiones del cabildo para, a continuación, decidir qué hacer con esa tierra y cómo ponerla en el mercado de bienes y a producir tanto para el desarrollo económico como para el fiscal, aunque sea de manera marginal, para lo cual generó una institucionalidad positiva que le dio al resto de actores sociales un marco de certidumbre. En este sentido, debe señalarse que el resto de actores, arrendatarios y enfiteutas aceptaron ese conjunto de reglas, pero a la vez tuvieron la libertad de generar un conjunto de informalidades a partir de las cuales condicionó, de alguna manera, la respuesta del cabildo que terminó por institucionalizarlas. En un marco estrictamente neoinstitucional lo que se puede ver es que la tierra tenía un conjunto de reglas de uso: lotificación, adjudicación, denuncia, subasta, titulación, y los atributos de la comunidad se empataban con las acciones concretas de cada una de esas reglas, es decir, había un margen de acción estrictamente delimitado. Así se propiciaba que la tierra fuera explotada y se pagara el arriendo o el canon establecido. Se dieron un conjunto de interacciones particularmente sobre el pago de las obligaciones fiscales que culminaron con desenlaces en los que el gobierno municipal adecuó sus criterios para adaptarse a una sociedad que creaba esquemas de intercambio, usufructo e, incluso, posesión del bien que no estaban en el presupuesto de la municipalidad (Poteete, 2012: 100). 
¿Cómo son definidos los bienes que pueden convertirse en los objetos y sujetos de propiedad?

Este fue el tema en el cabildo. ¿Cómo lograr el control de un territorio que no le pertenece a nadie porque está abandonado, pero sobre el que pesan títulos, mercedes o algún documento que avala su posesión? ¿Cómo repartir tierras sobre las cuales el gobierno municipal no tiene ningún derecho de propiedad? Una vez resuelto el tema de a quién le pertenecen, ¿qué sigue?, ¿la municipalización? Y eso llevó no solo a anular los documentos que tenían los antiguos pobladores de la ciudad y que avalaban la posesión de un terreno, sino también a un convertir en ejidos municipales todo aquello que estuviese abandonado, lo cual marginó a un actor que debió aparecer a lo largo del siglo XIX, pero que no lo hizo: el gobierno general. Las leyes que se dictaron para unificar el conjunto de derechos de propiedad que existían en Guatemala partieron de un principio: se protegería a los ejidos de las ciudades y los pueblos. Por tanto, al declarar como ejidos las tierras del ayuntamiento los retiraban de la posibilidad de privatización que se buscó desde 1824 (Ávila, 2017a). Así que la definición de los bienes sujetos de derechos de propiedad se estableció con un principio: pertenecer a los ejidos municipales.

¿Cuáles individuos o entidades colectivas tienen qué derechos?

En otros trabajos ya citados aquí he hablado de que el gobierno de Antigua Guatemala lo que hizo fue organizar el territorio y la relación gobierno-población con instituciones de Antiguo Régimen y valores liberales. La enfiteusis, por ejemplo, fue dada a los individuos en pos de su desarrollo económico y el de sus familias por ser ciudadanos de Antigua, no por pertenecer a corporación alguna. De hecho, no hay evidencia de una relación simbiótica, cómplice o comparsa del gobierno y la jerarquía católica en el municipio. Prueba de ello es que el conjunto de edificios religiosos que no fueron reclamados cuando el apercibimiento de 1821, fueron incluidos en los ejidos y, por tanto, sujetos de apropiación, reparto y adjudicación.

En suma, el cabildo antigüeño promovió el individualismo económico y, por tanto, el político. Tampoco hay evidencia documental de que alguien haya sido discriminado por su raza en el acceso a la tierra. Es decir, aparentemente, partió del pilar fundacional del liberalismo: la igualdad jurídica. 


\section{Siglas}

$\begin{array}{ll}\text { AMCAG } & \text { Archivo Municipal de la Ciudad de Antigua Guatemala } \\ \text { FA } & \text { Fondo Administración } \\ \text { FP } & \text { Fondo Patrimonio } \\ \text { FG } & \text { Fondo Gobierno } \\ \text { RCyC } & \text { Ramo Calles y Callejones } \\ \text { RE } & \text { Ramo Ejidos } \\ \text { RP } & \text { Ramo Patrimonio }\end{array}$

\section{Fuentes de consulta}

Ávila Quijas, Aquiles Omar, 2012, "Interpretaciones sobre la redención de censos enfitéuticos en Guatemala a finales del siglo XIX. Los casos de Antigua Guatemala, San Felipe y San Mateo Milpas Altas", Mundo Agrario, 13(25), Buenos Aires, Universidad Nacional de la Plata, en: <http://mundoagrario.unlp.edu.ar/article/ view/MAv13n25a13>.

Ávila Quijas, Aquiles Omar, 2014, El ayuntamiento de Antigua Guatemala y la administración de sus ejidos. De la enfiteusis a la propiedad privada, 1818-1885, tesis doctoral inédita, México, El Colegio de México.

Ávila Quijas, Aquiles Omar, 2017a, "Ejidos: una categoría bisagra en la formación de los derechos de propiedad en Antigua Guatemala, siglo XIX", en Antonio Escobar Ohmstede, Romana Falcón y Martín Sánchez Rodríguez (coords.), La desamortización civil desde perspectivas plurales, México, El Colegio de México/El Colegio de Michoacán/ Centro de Investigaciones y Estudios Superiores en Antropología Social, pp. 519-545.

Ávila Quijas, Aquiles Omar, 2017b, "La redención de censos enfitéuticos: Antigua Guatemala (1877-1885)", en Estudios Jaliscienses, 108, pp. 48-59.

Azuela, Antonio, Herrera Carlos y Saavedra-Herrera Camilo, 2009, "La expropiación y las transformaciones del estado", Revista Mexicana de Sociología, 71(3), pp. 525-555.

Bavel, Bas van y Richard Hoyle, 2010, "Introduction: social relations, property and power in the North Sea area, 500-2000", en Bas van Bavel y Richard Hoyle (eds.), Rural economy and society in North Western Europe 500-2000, Bélgica, Brepols, pp. 1-23.

Béaur, Gérard y Jean-Michel Chevet, 2013, "Institutional changes and agricultural growth" en Gérard Béaur, Phillipp Schofield, Jean-Michel Chevet, y María Teresa Pérez Picazo (coords.), Property rights, land markets and economic growth in the European Countryside (Thirteenth-Twentieth Centuries), Bélgica, Brepols, pp. 19-68.

Castellanos Cambranes, Julio, 1992, "Tendencias del desarrollo agrario en el siglo XIX y surgimiento de la propiedad capitalista de la tierra en Guatemala", en Julio Castellanos Cambranes (ed.), 500 años de lucha por la tierra. Estudios sobre propiedad rural 
y reforma agraria en Guatemala, vol. 1, Guatemala, Facultad Latinoamericana de Ciencias Sociales, pp. 279-347.

Castellanos Cambranes, Julio, 1996, Café y campesinos. Los orígenes de la economía de plantación moderna en Guatemala, 1853-1897, Guatemala, CATRIEL.

Congost, Rosa, 2007, Tierras, leyes, historia. Estudios sobre "la gran obra de la propiedad", Barcelona, Crítica.

Congost, Rosa y Rui Santos, 2010, "From formal institutions to the social contexts of property", en Rosa Congost y Rui Santos (eds.), Contexts of Property in Europe, The Social Embeddedness of Property Rights in Lan Historical Perspective, Bélgica, Brepols Publisher, pp. 15-38.

Congost, Rosa, Piere Grife y Enric Saguer, 2011, "The role of emphyteutical practices in the social and economic transformations of Catalonia, XVIII-XX centuries", ponencia presentada en el XIII Seminari d'Historia Económica i Social. Les practiques enfitéutiques a l'epoca Moderna i Contemporanea, Una perspectiva comparada, junio 16-18, España, Universidad de Girona.

Fernando Pablo, Marcos, 2012, "El procedimiento expropiatorio: doscientos años de garantía de la propiedad", en Salustiano de Dios, Javier Infante, Ricardo Robledo, Eugenia Torijano (coords.), Historia de la propiedad. La expropiación, Salamanca, Ediciones Universidad de Salamanca/Servicio de Estudios del Colegio de Registradores, pp. 517-538.

Ferreira Esparza, Carmen Adriana, 1999, "El crédito colonial en la provincia de PamplonaNueva Granada: usos del censo consignativo", Signos Históricos, 1(1), México, Universidad Autónoma Metropolitana-Iztapalapa, pp. 59-84.

García Ruiz, Luis Juventino, 2015, "Demandas sociales y propiedad imperfecta en Veracruz: el impulso a la enfiteusis (1760-1811)", Secuencia, 93, México, Instituto Mora, pp. 28-49.

Gallego Anabitarte, Alfredo, 1998, Reparto y venta de tierras concejiles: llusión y derecho (los Montes de Toledo), España, Montecorvo.

Gómez Serrano, Jesús, 2000, Haciendas y ranchos de Aguascalientes. Estudio regional sobre la tenencia de la tierra y el desarrollo agrícola en el siglo XIX, México, Universidad Autónoma de Aguascalientes/Fomento Cultural Banamex.

Johnston Aguilar, René, 1997, De Santiago de Guatemala a la Villa de la Antigua Guatemala. Transformación y vida social ante una crisis, tesis de licenciatura inédita, Guatemala, Universidad del Valle de Guatemala,.

Mathieu, Paul, 2003, "Cambios Estructurales y desarrollo de las transacciones de tierra en África subsahariana", en Eric Leonard, André Quesnel y Emilia Velázquez (coords.), Políticas y regulaciones agrarias. Dinámicas de poder y Juegos de actores en torno a la tenencia de la tierra, México, Centro de Investigaciones y Estudios Superiores en Antropología Social/Institute du Recherche pour le Développement, pp. 101-127.

McCreery, David, 1994a, Rural Guatemala, 1760-1940, California, Stanford Universtity Press.

McCreery, David, 1994b, "El impacto del café en las tierras de las comunidades indígenas: Guatemala, 1870-1930", en Héctor Pérez Brignoli y Mario Samper (comps.), 
Tierra, café y sociedad, Costa Rica, Facultad Latinoamericana de Ciencias Sociales, pp. 227-278.

Mendoza García, Édgar, 2008, “De condueñazgo a municipio. El caso de Tlacotepec Plumas, Oaxaca, 1863-1901", en Antonio Escobar Ohmstede, Martín Sánchez Rodríguez y Ana Gutiérrez Rivas (coords.), Agua y tierra en México siglos XIX y XX, México, El Colegio de Michoacán/El Colegio de San Luis, pp. 187-208.

Mendoza García, Édgar, 2007, "La desamortización de la propiedad comunal en los pueblos cocholtecos 1856-1900", en Carlos Sánchez Silva (coord.), La desamortización civil en Oaxaca, México, Universidad Autónoma Metropolitana/Universidad Autónoma Benito Juárez de Oaxaca, pp. 65-101.

Mendoza García, Édgar, 2006, "El municipio de Tepelmeme, Oaxaca, y el uso de la legislación liberal, 1856-1908", en José Alfredo Rangel Silva y Carlos Ruiz Medrano (coords.), Discursos públicos, negociaciones y estrategias de lucha colectiva. Aportaciones al estudio de las movilizaciones sociales en México, siglos XVIII y XIX, México, El Colegio de San Luis/Archivos Histórico del Estado de San Luis Potosí, pp. 149-178.

Musset, Alain, 2011, Ciudades nómadas del Nuevo Mundo, México, Fondo de Cultura Económica

Porskrog Rasmussen, Carsten, 2010, "An English or a continental way? The great agrarian reforms in Denmark and Schleswig-Holstein in the late eighteenth century", en Rosa Congost y Rui Santos, (eds.), Contexts of Property in Europe, The Social Embeddedness of Property Rights in Land. Historical Perspective, Bélgica, Brepols Publisher, pp. 125-144.

Poteete Amy; Marco Janssen y Elinor Ostrom, 2012, Trabajar juntos: acción colectiva, bienes comunes u múltiples métodos en la práctica, México, Universidad Nacional Autónoma de México/Centro de Investigación y Docencia Económica/El Colegio de San Luis/Fondo de Cultura Económica/Universidad Autónoma Metropolitana.

Rosas Vargas, Rocío y Emma Zapata Martelo, 2012, "Mujeres y tenencia de la tierra en Salvatierra Guanajuato", Ra Ximani, 8(2), México, pp. 231-230.

Rubio Sánchez, Manuel, 1989, Monografía de la ciudad de Antigua Guatemala, 2 vols. Guatemala, Tipografía Nacional.

Taracena Arriola, Arturo, 1993, "Liberalismo y poder político en Centroamérica (18701929)", en Víctor Hugo Acuña Ortega (ed.), Historia general de Centroamérica. Las repúblicas agroexportadoras, tomo IV, España, Comunidades Europeas/Sociedad Estatal Quinto Centenario/Facultad Latinoamericana de Ciencias Sociales, pp. 167-253.

Tarrio García, María y Luciano Concheiro Bórquez, 2006, "Chiapas: Los cambios en la tenencia de la tierra", Argumentos, 19(51), pp. 31-71. 